\title{
Novos paradigmas literários
}

\author{
Denise Azevedo Duarte Guimarães
}

\begin{abstract}
Os artistas oferecem situações sensíveis com tecnologias, pois percebem que as relações do homem com o mundo não são mais as mesmas depois que a revolução da informática e das comunicações nos coloca diante do numérico, da inteligência artificial, da realidade virtual, da robótica e de outros inventos que vêm irrompendo no cenário das últimas décadas do século XX.
\end{abstract}

Diana Domingues

\section{Introdução}

Neste início de século XXI, momento em que tanto o corpo humano quanto o mundo analógico sofrem os desafios da clonagem, das experiências genéticas, da inteligência artificial e da realidade virtual, o homem deve repensar sua relação com a tecnologia como uma forma não de celebrá-la, mas sim de tratar questões humanas. De acordo com recentes pesquisas na área, o cidadão conectado quer um mundo pluralista, diversificado e mais humano. Nesse sentido, é preciso investigar de que modo as grandes modificações, sentidas em todo o mundo a partir da aliança entre as telecomunicações e a informática, têm repercutido nas manifestações culturais. Haveria um "novo enciclopedismo" associado à incorporação das tecnologias de ponta?

Toda investigação sobre a cognição, a produção do conhecimento e a criação artística na cibercultura deverá partir necessariamente da discussão do conflito "arte versus tecnologia" e de sua contextualização, tanto na diacronia quanto na sincronia. Cumpre, portanto, enfocar prioritariamente as enormes mudanças produzidas pela absorção das tecnologias eletrônicas e digitais no próprio conceito de conhecimento. Isso implica 
estudar como se produzem e se recebem informações, como as pessoas se relacionam com a multiplicidade de manifestações culturais nos multimeios, e mesmo os modos de interação possibilitados pelas novas tecnologias.

Na cena contemporânea, a complexidade de uma arte vista como "interarte" serve, cada vez mais, para aguçar os instrumentos que o homem possui para apreensão do mundo tecnológico que o rodeia. Seu domínio, que é o da sensibilidade, do não-racional, do inefável, rejeita toda intenção redutora, explicativa ou sistematizante.

Em todos os tempos, à medida que a ciência e a tecnologia avançam, novas contribuições são continuamente previstas nos termos da adaptação de instrumentos e materiais inovadores aos propósitos dos artistas. No fim do século XX, após o software ter superado o hardware, os programas de criação passaram a ocupar mais espaço no discurso artístico, em detrimento dos suportes ou dos objetos em si. Tal fato descortinou novos horizontes para uma discussão da literatura computacional, bem como das poéticas tecnológicas, uma vez que nelas as trocas simbólicas se intensificam e se modificam em função de meios cada vez mais refinados. $\mathrm{O}$ artista digital - escritor, poeta ou videomaker, entre outros - trabalha com imagens armazenadas na memória do computador: ele as manipula esteticamente, processa-as e edita-as por meio de recursos de última geração. O resultado almejado, além de "quebrar o gelo" da tecnologia, proporciona o refinamento das possibilidades poéticas e estéticas em meio digital.

A história das conquistas tecnológicas, repleta de exemplos de como o homem delas se apropria e as transforma para poder criar, distancia-se cada vez mais das ideologias meramente pragmáticas. Desse modo, as novas tecnologias, além de se destinarem ao aumento da eficiência e à redução do trabalho humano, identificamse com a produção do conhecimento e com a criação de formas artísticas. Na direção oposta, a obra de arte contemporânea perde sua hegemonia e se aproxima da tecnologia como estratégia de sobrevivência. Entendemos que assim a arte, em interface com as máquinas, busca nova energia no universo cibernético.

\footnotetext{
${ }^{1} \mathrm{O}$ termo "interarte", na acepção de uma arte interativa, emergente na pósmodernidade, foi originalmente utilizado por mim em trabalho publicado em 1995. Cf. Guimarães, Denise. "Arte, antiarte, interarte." Em: História da literatura. Prée pós-modernidade. Curitiba: Associação Cultural Avelino Vieira, 1995, p. 23-34.
} 
A situação, no entanto, não é pacífica. De um lado, constatamos que uma recusa obstinada em admitir a emergência de novos paradigmas literários, em nome de um purismo passadista, torna realmente difícil compreender como se pode refletir acerca das textualidades contemporâneas; de outro, vemos o esforço de alguns teóricos para entender as lógicas que estão por trás dos hipertextos informatizados, procurando desvendar como eles estão criando novos elementos e em que medida se remetem às reflexões teóricas anteriores acerca do texto literário impresso.

\section{O processo criativo}

As tecnologias interativas do computador simulam, com suas redes e memórias, operações do pensamento e do raciocínio. Possuem ferramentas que permitem ao usuário processos mentais próprios às atividades criativas, extremamente importantes para a formação do indivíduo.

Teoricamente, o processo criativo é um modo de interação humana com o mundo que se opõe a um modo técnico (ou sistemático) de interação. Decorre daí que, quando queremos produzir algo ou resolver um problema, podemos optar entre estratégias criativas e estratégias técnicas, que são diferentes em termos tanto práticos quanto de valores, como indicado no quadro abaixo:

\begin{tabular}{ll}
\multicolumn{1}{c}{$\begin{array}{c}\text { Tendências na } \\
\text { prática criativa }\end{array}$} & \multicolumn{1}{c}{$\begin{array}{c}\text { Tendências na } \\
\text { estratégia técnica }\end{array}$} \\
\hline $\begin{array}{l}\text { explorar representações visuais, espa- } \\
\text { ciais, de textura e de áudio; }\end{array}$ & $\begin{array}{l}\text { usar o formalismo e representações } \\
\text { simbólicas; }\end{array}$ \\
\hline evitar a abstração de detalhes e valor; & $\begin{array}{l}\text { buscar a certeza, a correção, a comple- } \\
\text { tude e o detalhe; }\end{array}$ \\
\hline $\begin{array}{l}\text { acolher a ambigüidade por possibilitar } \\
\text { a riqueza de significado; }\end{array}$ & eliminar a ambigüidade; \\
\hline $\begin{array}{l}\text { pôr em ação nossa intuição e imagi- } \\
\text { nação. }\end{array}$ & usar o raciocínio lógico.
\end{tabular}

Precisamos dos dois modos de interação com o mundo, pois cada um deles, dependendo da natureza da tarefa, pode se mostrar mais ou menos eficiente. Além disso, a associação dos dois sempre é necessária. 
(Jakobson, Roman. Lingüistica e comunicação. São Paulo: Cultrix, 1970: 128)

"(Pignatari, Décio. Semiótica e literatura. São Paulo: Perspectiva, 1974: 114)

(Pignatari, Décio. Comu nicação poética. São Paulo: Cortez / Moraes, 1979: 5)
Esses dois modos de interação com o mundo estão relacionados com a expressão (ligada aos sentimentos) e com a comunicação (ligada aos signos simbólicos, que são signos regidos pela convenção). A expressão diz respeito à indicação de sentimentos, à emissão de sinais que mostram o que o emissor está sentindo. Implica a ambigüidade e solicita um esforço interpretativo do receptor. Conotação, sugestão, subjetividade e liberdade são seus princípios. A comunicação, por sua vez, liga-se à transmissão menos ambígua possível de idéias e significados conceituais. É a exatidão da mensagem que importa. Seus pressupostos são a denotação, a explicitação, a objetividade e o compromisso com o real ou com a verdade.

Tal distinção nos leva diretamente à teoria de Roman Jakobson sobre a função poética da linguagem*, que não elimina os princípios da organização lógica da linguagem, incorporando a eles o raciocínio analógico. É isso que conferirá à linguagem poética sua dimensão ambígua e auto-reflexiva - diríamos, hoje, seu diferencial estético.

A tradução da teoria lingüística jakobsoniana sobre a função poética em termos semióticos realizada por Décio Pignatari ajuda a esclarecer esse ponto:

A LINGUAGEM VERBAL/ PARTICULARMENTE A LINGUAGEM SIMBÓLICA PEIRCEANA/ ADQUIRE A TÃO-FALADA FUNÇÃO POÉTICA, QUANDO UM SISTEMA ICÔNICO LHE É INFRA, INTRA E SUPER IMPOSTO. O corolário disto: [...] quando uma sintaxe analógica é superposta a uma sintaxe lógica."

Nos termos do autor, como a justaposição de elementos própria à sintaxe analógica, ou seja, a construção paratática, tende a destruir a linearidade, cria-se um movimento decorrente da organização sonora que se reflete na organização espacial, fazendo com que, em um poema, as rimas e ritmos sejam ícones. Fazer poesia é transformar o símbolo em ícone, uma sintaxe lógica em uma sintaxe analógica, os signos-para em signos-de: "Mas quando você foge desse automatismo, quando você começa a ver, sentir, ouvir, pesar, apalpar"*.

O crítico toca em um ponto essencial para o entendimento do poético, que se aplica também ao fenômeno literário contemporâneo: a desautomatização do trabalho com os signos verbais seja na instância de criação, seja na leitura dos textos. Em resumo, diz Pignatari, como um ser de linguagem, o poema é um processo de transcodificação semiótica porque: 
[...] rompe a chamada linearidade do discurso, na medida mesma em que é ambígua, pois que a ambigüidade do signo poético resulta de este ser um signo em profundidade - um signo que se afasta do automatismo verbal, um signo vertical espesso, cuja espessura resulta de camadas de signos embutidos em palimpsesto, gerando simultaneidade de informação e tendendo a ou sendo um ideograma - um ícone.*

Segundo a semiótica peirceana*, o signo verbal é simbólico porque representa seu objeto por força de uma convenção, norma ou lei; o signo indicial indica ou aponta para seu objeto, enquanto o signo icônico representa seu objeto por similaridade e corresponde, portanto, a uma sensação, a uma percepção livre de condicionamentos. Vale dizer que, para Peirce, o ícone é um tipo de signo que representa seu objeto por similaridade, correspondendo ao likenesss (forma pura do reconhecimento do mundo), o que, em termos lingüísticos, diria respeito a um signo motivado, ao passo que o signo verbal é um símbolo (um tipo de signo decorrente de uma convenção), que, sob a perspectiva lingüística, seria um signo arbitrário.

Peirce assinala que a capacidade de apreensão do que é semelhante pode subdividir-se em três formas de relação entre elementos ${ }^{*}$, de acordo com o esquema abaixo:

imagens - a relação entre elementos é criada pela duplicata das aparências do real, por intermédio de modelos;

diagramas - dizem respeito ao reconhecimento proporcional das partes e suas respectivas relações;

metáforas - referem-se ao reconhecimento de similaridades entre constituintes essenciais das partes.

É preciso esclarecer que, sendo a semiose um processo ininterrupto, o signo é múltiplo e variável, pois permanece em diálogo com o que está sendo interpretado. Desse modo, os poderes evocativo (icônico), indicativo (indicial) e significativo (simbólico) não são estanques: nenhum signo pertence exclusivamente a um desses tipos. Em qualquer processo sígnico, há a predominância de um desses valores sobre os demais: na arte predomina o ícone, os sinais de trânsito são sobretudo indiciais e o símbolo prevalece no discurso científico. As distinções metodológicas feitas na semiótica aplicada são ditadas pelas exigências internas da análise, ou seja, dependem do contexto da atualização desses signos e do ponto de vista da observação escolhido.
"(Ibid: 72).

" (Pierce, Charles Sanders. Semiótica. São Paulo: Pers. pectiva, 1990)
"(Peirce, Charles Sanders Escritos coligidos. São Pau lo: Nova Cultural, 1989: 58) 
(Morin, Edgar. O método III/1. Lisboa: Europa/Amé rica, 1986).

"(Eco, Umberto Obra aber. ta. São Paulo: Perspectiva, 1979: 92).
A aproximação entre os raciocínios lógico e analógico, vale dizer, entre arte e ciência, é ostensiva na plataforma da tecnologia digital, algo que já aparece na etimologia do termo tecnologia (do grego: tekhnologia) e se refere ao tratamento sistemático de uma arte ou artesanato. É nessa aproximação que as poéticas tecnológicas da contemporaneidade estão baseadas - uma aparente contradição de termos. Em outras palavras, trata-se do paradoxo da arte cibernética, que exige do poeta o mesmo que de um profissional de sucesso: a capacidade de, para obter o máximo de eficiência, empregar tanto a tecnologia quanto a criatividade. Do exposto infere-se, por exemplo, que os multimeios, ao oferecer recursos imaginativos e motivadores para a exploração de diversos temas, podem ser usados para liberar a criatividade.

Essa, aliás, parece ser a resposta à indagação sobre o auxílio ou não da tecnologia aos processos humanos criativos. O computador, no entanto, está fortemente associado a uma prática rotineira e mecânica, nada criativa. Ele não seria mais que uma simples ferramenta que faz os alunos gastarem horas nada recompensadoras diante de um monitor, sem que desenvolvam uma única idéia.. Em contrapartida, podemos atestar que, muito embora a técnica não possa, por si só, gerar algo radicalmente novo, seres humanos criativos sabem se apropriar das possibilidades tecnológicas e reinterpretá-las, comprovando os valores da prática criativa em multimeios. Lembramos Umberto Eco, que aborda a questão em Obra aberta e identifica na arte contemporânea uma nova forma de riqueza a que o autor moderno se propõe como valor a realizar.

É um valor que não se identifica teoricamente com o valor estético, pois se trata de um projeto comunicativo que deve incorporar-se numa forma bem-sucedida para tornar-se eficaz; e que somente se realiza se amparado por aquela abertura fundamental própria de toda forma artística bem-sucedida."

O autor considera essa espécie de abertura de segundo grau visada pela arte contemporânea um acréscimo e uma multiplicação das significações possíveis de uma mensagem ou, mais especificamente, um acréscimo de informação estética. Após desenvolver uma série de explanações que considera imprescindíveis ao entendimento dos princípios gerais da teoria da informação, para que possam ser conectados às teorias do texto poético moderno, chega à conclusão de que:

tudo isso significa somente que o poeta contemporâneo constrói sua mensagem poética com meios e sistemas diferentes dos do 
poeta medieval: não se discutem os resultados, e uma análise de obra de arte em termos de informação não visa avaliar seu resultado estético, mas limita-se unicamente a esclarecer algumas das

suas características e possibilidades comunicativas.*

O que se pode verificar, com certeza, é que, em grande parte da arte contemporânea, os recursos tecnológicos propiciam uma investigação criativa tanto dos meios quanto dos processos, auxiliando a desenvolver visões mais adequadas ao mundo pós-moderno, uma vez que libertam os artistas de modelos e conceitos preexistentes.

É inegável que os recursos de multimídia são ferramentas poderosas para o artista de hoje, proporcionando-lhe versatilidade e rapidez. As estruturas de hipertexto permitidas por alguns softwares oferecem inúmeras opções ao criador de uma obra de arte e, ao mesmo tempo, possibilitam ao fruidor/leitor/espectador navegar pelas telas de forma criativa, lúdica e sofisticada. Desse modo, a linguagem da arte, fugindo ao estático, passa a ser intrinsecamente dinâmica e interativa, uma vez que se liga aos modelos mentais e às estruturas narrativas de nível superior possibilitados pela informática contemporânea. Atualmente, os métodos de agenciamento de significações são procurados na rede de interfaces, cujas conexões em estrela inviabilizam qualquer leitura linear, fazendo com que o ato de leitura do objeto estético se torne análogo ao da "navegação". Assim como na poesia, o leitor "navegante" entra em contato com técnicas informatizadas que substituem a retórica, podendo manipular mundos possíveis ad infinitum. É por isso que as obras criativas contemporâneas, especificamente as literárias, que são o objeto de nosso estudo, demandam uma densa relação fruitiva e exigem análise e interpretação dos processos sígnicos que envolvam tecnologia e technë poietikè.

\section{$O$ ato de leitura}

Pode-se constatar que, na instância de recepção, o surgimento dos textos literários em novos suportes provocou uma verdadeira revolução no que se entendia como ato de leitura. As palavras estão lá, com toda sua carga de significações possíveis, porém o importante é perceber que as significações eclodem do encontro entre linguagens, uma vez que os textos literários multimidiáticos falam simultaneamente com diferentes sistemas de signos digitais e analógicos. 
(Kerckove, Derrick de. "A arquitetura da inteligência: interfaces do corpo, da mente e do mundo". Em: Arte e vida no século XXI: tecnologia, ciência e criati vidade. São Paulo: UNESP, 2003: 17).
$\mathrm{Na}$ leitura de um livro, cada leitor determina o tempo necessário para se deter em uma frase ou em um verso de um poema, por exemplo, e dar-lhe sentido, o que, em psicologia, denomina-se closure, ou seja, o ato de consciência que reconhece uma informação e fecha o processo após registrar o que é digno de nota. As mídias eletrônicas, todavia, determinam a duração da atenção, interferindo radicalmente na apreensão dos significados. Disso decorre, por exemplo, a crítica feita à televisão em geral de manter o espectador em um modo receptivo não crítico - ela não dá tempo para o fechamento, para o registro completo do conteúdo das mensagens.

Quando a pessoa lê, pensa com base em palavras que levam o mundo para sua tela mental. Ela traduz as palavras em imagens, imagina lugares e pessoas, faz com que elas se movimentem, como se estivesse projetando um filme sobre uma tela interna. Com as telas externas, sobretudo a televisão, a orientação da situação cognitiva se inverteu. Segundo Derrick de Kerckove: as sínteses psicossensoriais passaram a ser praticamente coletivas, "a tela é o portal onde se forma a mente pública"*.

Diante de um livro, controlamos o movimento de leitura; com a TV, somos controlados, pois as mídias eletrônicas determinam a velocidade do processamento da informação e, portanto, a razão estímulo-resposta; sendo assim, "administram nossas respostas sensórias: as mídias editam o usuário”* Kerckove lembra que, graças ao sistema alfabético, desde a Antigüidade, principalmente do Renascimento até os tempos modernos, o viés sensório dominante foi a visão. Em outras palavras, devido ao letramento alfabético que redistribuiu as prioridades cognitivas do sistema visual, passou-se do ato primitivo de simplesmente capturar o objeto visual à análise dos objetos da visão. No século $\mathrm{XX}$, a eletricidade presente nas tecnologias da informação inverte o processo, trazendo de volta a prevalência de capturar em relação a analisar. Nos termos do autor: "Enquanto o processo de letramento incentiva o desenvolvimento da imaginação privada, subjetiva, o mundo da realidade virtual cria um lugar e um tempo imaginário objetivos"**

No mesmo ensaio, todavia, Derrick de Kerckove expõe sua crença de que, à diferença da televisão, os computadores e a internet restauram a possibilidade do referido fechamento (closure) porque o usuário pode decidir quanto tempo dedicará a cada informação que aparece na tela. Desse ponto de vista, a duração da atenção, por exigir estratégias de leitura e de visualização em 
certo sentido individuais, pode até mesmo melhorar a qualidade da atenção, uma vez que o computador e a internet proporcionam um "razoável grau de independência psicológica"*

As mídias também determinam que tipo de associações mantemos com os vários conteúdos que elas produzem para nós. Por exemplo: hoje a world wide web nos proporciona um ambiente incrível de associações que estão permanentemente disponíveis. Estamos acostumados a cultivar associações dentro de nossa cabeça; agora podemos cultivá-las fora e podemos ter acesso a enormes quantidades de recombinações potenciais de informações.*

Desse modo, a consciência de que podemos cultivar e manter uma identidade privada e "ao mesmo tempo compartilhar o processo de informação com um grupo seleto sem sermos eliminados pela identidade do grupo"* leva a uma responsabilidade com um tipo de habilidade de resposta que precisa ser desenvolvido no processamento de informação. Verifica-se, em âmbito mundial, o desenvolvimento de um novo tipo de mente conectiva que ultrapassa a dicotomia mente individual (na leitura) versus mente coletiva (nas mídias eletroeletrônicas). Essa mente conectiva elimina o leitor e o espectador, e cria a figura do "usuário-interagente"**

Sem dúvida, tal interatividade pode ser adequadamente direcionada a novas práticas artísticas, algo que nos leva ao pensamento dos teóricos que acreditam que os novos códigos, as novas linguagens e a imagem eletrônica reduzem a distância entre culturas diferentes, transformam a maneira de nos comunicarmos e provocam mudanças na base filosófica das relações entre a vida e a arte, entre a ciência e a criatividade.

\section{Novos paradigmas da criação literária}

Identificam-se ao menos duas propostas literárias no espaço multimidiático: as narrativas hipertextuais e a poesia multimídia, diante das quais se pode perceber o papel fundamental que as teorias do texto das últimas décadas podem ter na compreensão das novíssimas textualidades informatizadas.

\section{As narrativas hipertextuais}

Um saber limitado ao modelo conceitual do texto impresso, em razão de seu caráter uniformizador e seriado, reduz o conceito de conhecimento, principalmente quando se trata da diversificação cultural na segunda metade do século XX.

Marshall McLuhan* foi um dos primeiros intelectuais a ques-

tionar a idéia de que o conhecimento é essencialmente um "saber

(McLuhan, Marshall. A ga láxia de Gutenberg. São Paulo: Cultrix, 1972; e Os meios como extensões do homem. São Paulo: Duas Cidades, 1969). 
(Machado, Arlindo. Má quina e imaginário: o desafio das poéticas tecnológicas. São Paulo: EDUSP, 2001 179.80).

(Pignatari, Décio. Comu nicação poética. Ob. cit.: 5). de livros", paradigma do humanismo do século XVI. "Mas se considerarmos que as mídias dão continuidade, em nosso tempo, ao projeto histórico do livro, é preciso também considerar que, nesse mesmo movimento, elas o transformam, redirecionando-o em razão das novas necessidades do homem contemporâneo"*

Hoje, amplia-se o conceito de livro, visto antes como memória externa e estática do homem, para o universo das mídias, com suas máquinas, no interior das quais o pensamento começa a ser trabalhado dinamicamente. Tem-se um livro eletrônico que faz dos leitores navegantes, em um mar de informações nãolineares. Ao operar por fragmentos, o leitor, como co-autor, edita e monta o hipertexto.

O que conhecemos como hipertex to eletrônico, termo usado por Theodor H. Nelson nos anos 1970, é um sistema de blocos de imagens eletrônicas, interligadas em trajetos múltiplos e com textualidade aberta, ou seja, sem finalização, que se representa como trama, rede ou constelação. Trata-se de uma estrutura textual não seqüencial que se bifurca e permite ao leitor a escolha de diferentes itinerários virtuais conectados entre si. Como esses blocos interligados não apresentam marca de início ou fim, o hipertex to é um sistema que pode ser descentralizado e centralizado infinitamente, já que qualquer documento ou página pode ser o ponto inicial que permite a linkagem, ou seja, a livre associação de uma parte a outra. Dito de outro modo, forma-se uma rede que se materializa a partir da interação do usuário e lhe permite navegar, segundo as conexões efetuadas por sua interpretação.

Diante das narrativas hipertextuais, efetivam-se as especificidades dos signos da arte literária, tais como a criação ou construção de formas representativas dos sentimentos, mas isso se dá de modo analógico e ambíguo. Tais formas se dirigem fundamentalmente às faculdades perceptivas humanas e não ao intelecto, pois a linguagem da arte, em vez de descrever os sentimentos, expressa-os esteticamente. $\mathrm{O}$ artista não diz. Ele mostra, presentifica, cria "modelos de sensibilidade", como ensina Décio Pignatari." O poeta "faz", "cria e recria" a linguagem.

No mesmo estudo sobre a obra de arte como obra aberta, Umberto Eco explica que cada leitor, como co-autor, deve completar seus sentidos de acordo com o próprio repertório. Isso quer dizer que os sentidos da obra aberta são inesgotáveis; ela oferece inúmeras possibilidades de interpretação, ou seja, cada 
tex to indica, sugere ou aponta os caminhos para interpretações pertinentes. Em Tratado geral de semiótica, define-se o "relevo semiótico do tex to estético"*. Resumidamente, pode-se entender esse relevo como um trabalho particular de manipulação da expressão que provoca um reajustamento do conteúdo, produz uma função sígnica original, provoca uma mutação de código e leva a um novo tipo de visão do mundo que, por sua vez, estimula um complexo trabalho interpretativo no destinatário e, finalmente, solicita respostas originais.

Tais conceitos, evidentemente, mostram-se bastante próximos das textualidades literárias em novos suportes. O texto literário eletrônico é algo extremamente dinâmico e aberto que assume, de modo radical, a multiplicidade de sentidos e a inesgotabilidade de interpretações inerentes a seu relevo semiótico peculiar. Como propõe Alkmar dos Santos, o hipertexto se destaca: a) pela efemeridade de suas manifestações; b) pela ausência de limites ou partes bem definidas; c) pelo desenvolvimento de nós e redes em ligações multilineares; d) pela fragmentação das leituras sucessivas que o hipertexto permite produzir; e) pela possibilidade de passar quase instantaneamente da parte ao todo; f) pela presença de grande quantidade de textos nãoverbais; g) pela disponibilidade de todo um aparato paratextual (referências, imagens, citações, remissões, concordâncias, bancos informacionais vários etc.) ${ }^{*}$.

Como explica esse autor, muitas dessas características são inerentes, porém não exclusivas do hipertexto. Há uma série de conceitos que sempre acompanharam o texto literário e podem ser extremamente importantes para elucidar essa nova modalidade textual. Aqui, ressaltamos que todo o esforço teórico das últimas décadas tem apontado sistematicamente para as características listadas acima, muitas delas, aliás, percebidas desde as propostas do barroco literário. Quando o engenho se sobrepõe à arte, a ruptura do equilíbrio clássico se apresenta no barroco como o predomínio da techne, ou seja, da técnica e do labor na produção poética, verificado nos mecanismos que levam ao discurso engenhoso, aos labirintos conceituais e formais, aos anagramas e às inovações técnicas e estilísticas, predominantemente lúdicas, que se dirigem mais ao olhar que à audição.

É nesse sentido que inúmeros textos literários da atualidade estabelecem uma ponte com a visão anamórfica e ambulante da
"(Eco, Umberto. Tratado geiótica. São Paulo: Perspectiva, 1982) "(Santos, Alckmar Luiz
dos. "Textualidade literária
e hipertexto informatiza-
do". Em: Anais do V Encon-
tro Nacional da ABRALIC.
Disponível em www.ufsc.
br/ alkmar/). 
"(Peixoto, Nelson Brissac. "Passagens da imagem: pintura, fotografia, cinema, arquitetura". Em: Parente, André (org). Imagem-máquina: do virtual. Rio de Janeiro Ed. 34, 1996: 239).
" (Fraga, Tânia. "Simula. ções estereoscópicas inte. rativas" Em. Domingues, Diana (org.) A arte no sé culo XXI: a humanização dastecnologias. São Paulo: das tecno 109ias. Săo Paul estética barroca. É o que observa Nelson Brissac Peixoto, ao estabelecer uma interessante relação entre o movimento na arte barroca e as imagens da arte contemporânea: "São múltiplos fluxos, em permanente devir. [...] Trata-se de uma transição porque, no barroco $[\ldots .$.$] , tudo escoa e verte em outra coisa, todo$ intervalo é lugar de um novo desdobramento"*.

Diríamos que desse movimento em dobras surgem novas relações entre as imagens, das quais emerge uma outra concepção do espaço e do tempo, tanto na instância de criação quanto na da leitura dos textos contemporâneos. Quando o verbal, além do sonoro, conjuga-se ao visual, percebe-se o hibridismo como configurador do procedimento compositivo barroco, no qual o signo verbal é trabalhado nas interfaces com outros códigos. Observe-se que os textos experimentais do século $\mathrm{XX}$, assim como ocorre no barroco, apostam em um gosto da descoberta e da percepção inesperadas. $\mathrm{O}$ jogo lingüístico se torna intelectual. A qualidade desse exercício de reflexão se comprova, sobretudo, em sua capacidade de reter a atenção e ocupar o pensamento do espectador/leitor durante o máximo de tempo. Evidencia-se desde então, portanto, a tendência da arte moderna de tornar o consumidor produtivo, ou seja, de lhe oferecer elementos que só em sua atividade se realizam como obras de arte, algo que encontrou nas escrituras hipertextuais um meio extremamente profícuo para seu desenvolvimento.

Fragmentação, intertextualidade, dialogismo, palimpsesto, signos intercambiantes entre o verbal e o icônico, obra aberta, entre muitos outros, são termos constantes no atual vocabulário crítico. A diferença é que, nas telas ou monitores, os materiais e a materialidade do hipertexto são diferentes, mas seus efeitos equivalem aos percebidos e já convenientemente estudados no texto impresso. Seria o momento, então, de nos debruçarmos sobre as especificidades do hipertexto, procurando entendê-lo como um trabalho literário que envolve novas modalidades sígnicas, que podem ser associadas ao comentário de Tânia Fraga em "Simulações estereoscópicas interativas":

Imerso no campo sensorial pré-definido, o indivíduo que o experimenta pode criar novos conjuntos de relação significantes. Ele amplia assim o mundo imaginativo que passa a compartilhar. Tem ele, também, a oportunidade de aumentar o seu acervo visual, de desenvolver e organizar o seu raciocínio lógico e analógico e de exercitar a sua criatividade. Este indivíduo pode mesmo aumentar o potencial de suas múltiplas inteligências, ampliando a sua consciência sígnica." 


\section{A poesia multimídia}

No momento que as imagens com palavras são retiradas do papel e visualizadas em uma tela, a obra poética deixa de ser estática e passa a incorporar o movimento e as sonoridades graças aos recursos de um software específico que configura um discurso virtual, eletrônico-digital e, portanto, diferenciado. Tal fato representa um marco para as poéticas da visualidade no diálogo estético mediado por máquinas, com o surgimento da poesia multimídia: os videopoemas ou clipoemas, no fim do século XX.

$\mathrm{O}$ termo videopoema (grafado com ou sem hifen) tem sido usado, no Brasil e em Portugal, desde os anos 1980, quando ocorreram algumas experiências pioneiras com a poesia em telas de computadores ou televisões. O termo clipoema, por sua vez, liga-se às experiências realizadas por videomakers e artistas que trabalhavam com computação gráfica na transcriação de poemas concretos para os novos suportes no início da década de 1990. Nesse momento, o vocábulo, em uma associação com videoclip, passou a ser empregado com ligeiras alterações na grafia em entrevistas e artigos por Augusto de Campos, Décio Pignatari, Walter Silveira e Júlio Plaza, entre outros. Oficialmente, o termo foi usado pela primeira vez no Brasil em 1994, na sexta edição de Perhappiness ${ }^{2}$, que exibiu clipoemas feitos com base em textos de Paulo Leminski.

As produções poéticas multimidiáticas somam várias mídias e oferecem estímulos de natureza visual e auditiva que proporcionam uma experiência estética marcada pela sinestesia (do grego sin, com, e aisthésis, sensação). A interconexão de várias impressões sensoriais, interligadas durante a recepção do tex to poético nas telas, provoca sensações que parecem se relacionar umas com as outras, de acordo com múltiplos dados que, sincreticamente, são estocados e se processam na memória, como estímulos em contaminação. Dessas associações espontâneas entre sensações de naturezas diferentes surge uma situação híbrida para a fruição do objeto artístico, inserindo-se em um espectro mais vasto, em que sinais emitidos por signos de linguagem tecnológica estão, em um processo de intersemiose, relacionados a poéticas verbais.

\footnotetext{
${ }^{2}$ Neologismo criado por Paulo Leminski e que dá nome ao evento anual da Fundação Cultural de Curitiba dedicado à literatura.
} 
(Parente, André (org). Imagem-máquina: a era das tecnologias do virtual. Ob. cit.: 286.
A poesia visual contemporânea, para nós, presta-se otimamente ao emprego dos meios audiovisuais, devido às inumeráveis possibilidades de tratamento do material poético; um tratamento que configura suas formas a partir de dentro e não como meros aparatos externos e estranhos à criação. Basta observar, por exemplo, poemas em multimeios em que, por intermédio de uma decisiva elaboração computacional, o aspecto gráfico final adquirido se integra perfeitamente às imagens obtidas pela síntese.

As diferentes poéticas tecnoeletrônicas podem ser examinadas à luz dos respectivos métodos criativos, uma vez que o conceito de multimídia supõe uma verdadeira integração dos meios, por meio de uma "interface eletrônica e amiga, ou seja, o computador"*. O termo não se reduz a uma simples justaposição mecânica de textos, sons e imagens, tendo seu sentido associado à hipermídia, ou seja, uma rede computadorizada e original de interfaces constituída por uma hibridação de traços tomados de empréstimo de várias mídias. Essa concepção só se tornou possível no momento em que as tecnologias de impressão e edição de textos, de gravação e impressão de sons e vozes, de gravação e transmissão de imagens, entre outras conquistas recentes, alcançaram a fase da eletrônica digital.

Desde a "revolução" da poesia barroca e, mais especificamente, com a revolução de Mallarmé, de que é tributária toda a poesia visual que se segue, o olhar do leitor percorre novos caminhos, em uma movimentação até então desconhecida. Abriram-se caminhos para novas possibilidades poéticas que procuram se adequar à linguagem da arte na era da máquina. O fenômeno ganhou ênfase nas vanguardas do início do século XX, em cujas produções poéticas se destaca a exploração dos efeitos visuais, em franco diálogo com as artes plásticas. É nesse sentido que o estudo do surgimento da lírica contemporânea, sob o viés das propostas das vanguardas e dos experimentalismos no transcurso do século XX, possibilita uma vinculação aos novos paradigmas da produção de poemas na passagem para os multimeios.

Resumidamente, podemos afirmar que, no que tange à poesia multimídia, alguns procedimentos análogos podem ser verificados: a) a distribuição não linear dos signos verbais na página; b) a utilização de diferentes tipos gráficos; c) a sintaxe desmembrada, origem da fragmentação da poética experimen- 
tal; d) a exploração das formas geométricas; e) os arabescos caligráficos; f) as estruturas anagramáticas; g) as estruturas labirínticas; e h) os apelos às ilusões de ótica.

No entanto, por mais radicais que tenham sido as experiências com a visualidade na poesia, textos impressos com palavras e imagens são bidimensionais; a terceira dimensão é sugerida pela perspectiva e, às vezes, pela cor. O projeto de Mallarmé demanda outro modo de produção e uma resolução técnica que só pôde ser vislumbrada modernamente. Nesse sentido, no fim do século XX, após o surgimento e o uso de novas tecnologias a serviço de processos criativos, parece natural que a poesia visual tenha passado a experimentar os meios eletrônico-digitais para estabelecer relações inusitadas entre palavra e imagem. Acreditamos, portanto, que o uso dos multimeios em poesia é uma decorrência natural das transformações radicais tanto na matéria (sua parte física) quanto no espaço e no tempo, que foram profundamente alterados pelas novas tecnologias.

Seguindo os passos de Mallarmé, a lírica do século XX explora as dissonâncias das quais resulta um tecido de tensões de forças absolutas na forma e no conteúdo. Consideramos que o poema visual expressa ostensivamente essas tensões e que, nesse contexto, a poesia concreta se tornou a base de toda a poesia visual das últimas décadas, bem como das recentes experiências poéticas em novos suportes. Como resultado, surgiu na poesia contemporânea uma linguagem híbrida que mistura estilos incompatíveis, ou seja, trata-se de uma poesia que utiliza o computador e os sistemas de produção de imagens em vídeo e em outras mídias para, por meio das refinadas potencialidades das recentes tecnologias, afirmar-se, cada vez mais, como invenção.

\section{A tipografia digital e o surgimento da poesia multimídia}

Tradicionalmente, a escrita tem sido concebida apenas como uma ferramenta para o registro de pensamentos e discursos verbais. Muitos artistas plásticos, poetas e designers gráficos, no entanto, têm tentado, há décadas, demonstrar o potencial do design tipográfico para provocar emoções e indicar relações, ultrapassando sua função simbólica e referencial. Essa tendência, originária da produção de cartazes litográficos no fim do século XIX, encontrou novo fôlego com o surgimento do modernismo, embora a visão logocêntrica da escrita continue a prevalecer entre os designers gráficos europeus e a expandir-se mundo afora. 
(Derrida, Jacques. A escritura e a diferença. São Pau lo: Perspectiva, 1971:230).

"(: 233).

"(Machado, Arlindo. Má quina e imaginário. $\mathrm{Ob}$ cit.: 212)
Jacques Derrida, ao discorrer sobre o logocentrismo na cultura ocidental, demonstrou que o logos (determinação metafísica da verdade) é inseparável da phone (substância fônica), implicando o recalque da palavra escrita em si. Segundo o filósofo francês, a visão logocêntrica da escrita prevalece há séculos, sendo necessário desconstrui-la, ou seja, desrecalcar o que foi estruturalmente dissimulado nos textos. Essa desconstrução pode ser entendida, portanto, como uma atividade de discussão e denúncia dos pressupostos e dos conceitos de base "logo-fono-etnocêntrica"*

Apenas na década de 1980, com o aparecimento do computador gráfico pessoal e a difusão da teoria desconstrutivista de Derrida entre estudiosos do design gráfico e da comunicação visual, a tipografia pôde manifestar todo o seu potencial comunicativo. Ao absorver as idéias de Derrida, os poetas aprenderam com os designers digitais novas maneiras de enfatizar os aspectos icônicos e indiciais dos signos verbais que estiveram recalcados durante séculos, por força da cumplicidade metafísica entre som e sentido. Pode-se dizer que aprenderam com Derrida que:

[...] há duas maneiras heterogêneas de apagar a diferença entre o significante e o significado: uma, a clássica, consiste em reduzir ou em derivar o significante, isto é, em submeter o signo ao pensamento; a outra, a que aqui dirigimos contra a precedente, consiste em questionar o sistema no qual funcionava a precedente redução: e em primeiro lugar, a oposição do sensível e do inteligível."

Segundo Arlindo Machado, foi em Portugal que, nos anos 1980, "o poeta Melo e Castro teve uma idéia pioneira de lançar mão do gerador de caracteres para produzir poemas animados, pensados especificamente para veiculação na televisão"* . Com o advento do gerador de caracteres, surgiram muitas possibilidades de criação para explorar textos na tela. Conhecido como GC, é basicamente um dispositivo concebido para gerar e inserir textos de diferentes tamanhos, tipologias e cores, sobrepondo-os ou não a imagens preexistentes. Os geradores são de dois tipos: o que é utilizado especificamente para isso em uma ilha de edição-linear e consiste em um aparelho conectado a um sistema de equipamentos de vídeo interligados (por exemplo, vídeo-player > gerador de caracteres > vídeorecorder), ou então o que utiliza um computador em uma ilha de edição não linear, em que o próprio software responsável pela edição de imagens fornece opções para a geração de caracteres. Atualmente, os dispositivos utilizados na produ- 
ção de vídeo permitem ao operador/criador uma infinidade de intervenções nas letras, palavras ou textos inteiros, em que este manipula a tipologia, distorcendo-a, criando fusões e animações com imagens, às quais podem ser integradas formas, cores e movimentos que apenas o novo espaço das telas pode oferecer. Esse processo de transformação das palavras se revela uma importante ferramenta para o poeta que procura os novos meios visando produzir um discurso iconizado e almeja transitar nos diversos campos semióticos que a mídia eletrônica oferece para efetivamente transcriar a poesia, adequando-a à cibercultura.

\section{Novas práticas significantes}

Percebe-se também que, do barroco à arte pós-moderna, a questão fundamental é a representação ligada à apreensão temporal. No meio desse caminho, a fotografia e o cinema têm papel fundamental, enquanto as artes buscam novos sentidos de perspectivismo e relativismo, para representar a dinâmica temporal e espacial da era da máquina.

Aceitar, conhecer e usar esteticamente as formas que vemos diariamente, as cores e luzes do nosso tempo, quer dizer expressar-se na linguagem de hoje, feita para o homem de hoje, um esforço que passa obrigatoriamente pelas narrativas hipertextuais e pela poesia multimídia. Assim, é importante assinalar que falar de multimídia cada vez mais corresponde a falar de um processo interativo gerado pelo computador que atua na instância de criação da obra, possibilitando a integração de informações e matérias de expressão advindas de mídias que não são tradicionalmente interativas.

\section{Videoarte \& videopoesia}

Na literatura ocidental, não é nova a imagem de uma produção literária criada diretamente por instrumentos, por máquinas ou mesmo por fórmulas. O molde poético de Quirinus Khulmann (1651-1689) é capaz de originar mais de seis bilhões de poemas diferentes com base em uma estrutura poética inicial. Sua idéia foi retomada na década de 1960, na França, por Raymond Queneau em Cent mille milliards de poèmes: trata-se de dez sonetos, com 14 versos cada um, em que, graças a um programa de computador, o leitor pode substituir cada um dos versos por um dos outros nove que lhe correspondem, ou seja, pode-se chegar a 100.000.000.000.000 sonetos diferentes."

\footnotetext{
(Donguy, Jacques. "Poe. sia e novas tecnologias no amanhecer do século XXI". Em. Domingues, Diana. Aarte no século XXI: a humaniza. ção das tecnologias. Ob. cit.: 263).
} 
Nos Estados Unidos, William Burroughs criou com a ajuda do matemático Ian Sommerville e o auxílio de um computador os poemas I AM THAT I AM, em 1959, e JUNK IS NO GOOD BABY, em 1961. Em 1963, no Brasil, o poema ACASO, de Augusto de Campos, foi permutado por computador. Interessante também é a homenagem da computer poetry a Apolllinaire, que em 1914 publicou o poema permutável LINDA. Em Londres, em 1968, Emmett Williams, com o apoio técnico de Peter G. Newmann, criou o poema GUILLAUME APOLLINAIRE: o nome do poeta francês está "escrito nas facetas de um diamante e as letras podem ser manipuladas no interior de formas geométricas"*.

Durante toda a década de 1970, inúmeros poetas, em todo o mundo, dedicaram-se a criar poemas com a ajuda dos computadores. Nesse contexto, dá-se a reunião de escritores, matemáticos e informáticos com o intuito de pôr o computador a serviço da literatura de todas as formas possíveis. Eles acreditam que a máquina é uma ferramenta programada para fazer o que se espera dela, repousando, portanto, a responsabilidade nos artistas. São estes quem criam e publicam várias antologias de Computer poems.

A novidade continua a ser explorada na França no início dos anos 1980, e as experiências vão do texto infinito aos ícones informáticos abstratos, passando por propostas interativas com revistas poéticas em disquete, em que o leitor pode intervir no texto. Formam-se grupos que tratam da escrita informatizada e desenvolvem-se softwares específicos. Poetas representativos fundam o grupo A.L.I.R.E., composto por autores de diversas nacionalidades. Donguy relata o lançamento de Alire $n^{\circ} 8$, em novembro de 1984, apresentado sob embalagem plástica:

[...] um texto animado de Patrick Burgaud (Holanda), um "hipertexto" de Jean-Marie Laffaile (França), um "gerador" de Pedro Barbosa (Portugal), um outro "gerador" de Pedro Barbosa e Abílio Cavalheiro (Portugal), um "poema performance" de Jacques Donguy e Guillaume Loizillon (França), um "gerador" de Jean-Pierre Balpe (França) e um "hipertexto" de Eduardo Kac (Estados Unidos).*

Ressaltamos que Eduardo Kac é brasileiro, radicado nos Estados Unidos, e criou hiperpoemas, com bifurcações vocálicas e consonantais, além de teorizar sobre hiperpoesia com a idéia de navegação através do poema. Em 2003, em depoimento para o vídeo $A r t<e>$ tecnologia.br, Kac disse acreditar que os princípios 
científicos podem informar o fazer artístico. Em suas obras, a ênfase nunca é na ciência, mas na arte, em como a ciência pode criar obras de impacto visual e efeito emocional.

Ao lançar mão dos novos materiais, dos novos recursos, os artistas continuam trabalhando com os meios de seu próprio tempo, como, aliás, sempre fizeram. O hipertex to informatizado se torna capaz de associar, de imediato, a matéria visual ao extrato verbal, concretizando o que antes era referência extratextual. Por meio de interfaces, são provocados acontecimentos em tempo real, introduzindo a simultaneidade das estruturas rizomáticas nos novos textos. Nesse sentido, alguns softwares, como poderosas ferramentas, oferecem infinitas opções aos artistas atuais. Ao mesmo tempo, na instância de recepção, o fruidor/leitor/espectador deve assumir, diante dos monitores, uma atitude criativa, lúdica e sofisticada.

Cumpre assinalar que a poesia multimídia não pode ser considerada um hipertexto na acepção mais ampla do termo, porém em suas idas e vindas, configurações mutantes, aproximações, afastamentos, paradas, variantes rítmicas de sons e imagens, que fazem com que o visual se relacione aos outros sentidos, a mente do intérprete remonta o todo. É inegável que a poesia, quando apresentada nas telas ou monitores, introduz na cena poética:

[...] a experiência vertiginosa da simultaneidade: não se trata mais de ler um texto poético, mesmo que complexo, mas de procurar dar conta de um grande número de textos poéticos que acontecem ao mesmo tempo, simultaneamente na tela e nos alto-falantes, mixados a partir de várias fontes diferentes. ${ }^{*}$

Em outros termos, nessas diversas conexões, a mente processa os sentidos e constrói o sentido poético, uma vez que a arte eletrônica e a multimídia ampliaram radicalmente o alcance das obras. Em decorrência, nossa percepção se transforma cada vez mais, assumindo novos ritmos e novas direções. O olhar do leitor/espectador/fruidor que já está familiarizado com o videoclipe, as vinhetas de abertura de programas e as mensagens publicitárias na TV, torna-se outro.

No novo horizonte de expectativas, devido a uma dinâmica transformação dos meios e das mensagens transmitidas, a poesia é impulsionada pela pluralidade sígnica da cibercultura. $\mathrm{Na}$ instância de criação, o poeta se comporta como o verdadeiro designer da linguagem ou com a maestria de um diretor de ci-

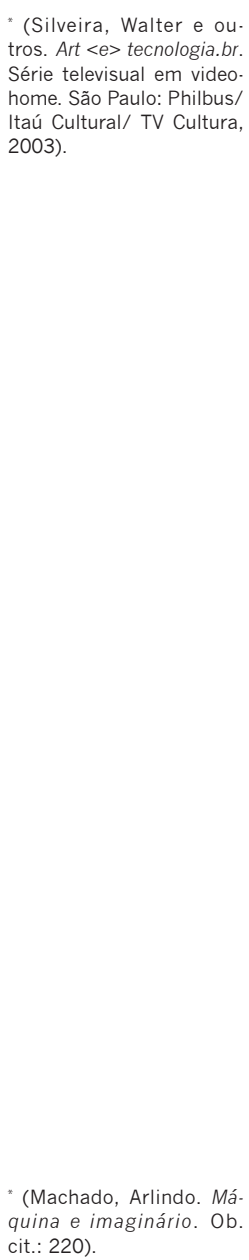

"Machado, Arlindo. Má quina e imaginário. Ob. cit.: 220). 
" (Araújo, Ricardo. Poesia visual, vídeo poesia. São Paulo:

*(: 167). nema, operando, com o devido apoio técnico, multitecnologias que vão da tipografia à computação gráfica.

Na década de 1950, aliás, os poetas do grupo concretista foram os primeiros a perceber, entre nós, as múltiplas possibilidades de experimentações poéticas que as novas tecnologias viriam a oferecer. Ao ver que poderiam confrontar múltiplas linguagens em seus poemas, isto é, o verbal, o visual, o vocal, o sonoro e/ou ruídos, mergulharam em um campo totalmente inexplorado e anterior aos computadores com recursos gráficos. As experiências concretistas se revelaram extremamente inovadoras e abriram um leque de possibilidades expressivas não só para a poesia, como também para o design gráfico em geral. Mesmo as artes plásticas se redimensionaram com as propostas do concretismo, que defendia uma arte multiconectada com as novas realidades mas, ao mesmo tempo, capaz de romper com a cópia da natureza - "ela é sua própria natureza”, como disse Waldemar Cordeiro, um dos líderes do Grupo Ruptura.*

No prefácio do Poetamenos - seis poemas artesanalmente impressos em até seis cores, publicados no n ${ }^{\circ} .2$ de Noigandres, em 1953 -, Augusto de Campos mostrou sua ânsia por novos meios que pudessem reforçar a plasticidade dos vocábulos, a sua tipografia e a sua distribuição (topografia) na página: “Mas luminosos, ou film-letras, que os tivera?” Bem depois, em 1994, testemunhou que "foram necessárias algumas décadas para que aquilo que parecia não passar de wishful thinking se transformasse em realidade"*.

Os artistas, desde sempre, efetuam a busca por novos suportes. Bach usou o cravo porque era o meio mais avançado de seu tempo, assim como Stockhausen usou os sintetizadores, que representavam, em sua época, a tecnologia de ponta em termos sonoros. É essa busca que tem se tornado marcante na arte contemporânea desde a consolidação da instalação, do objeto e da performance, nos anos 1960, até o aparecimento da videoarte entre 1970 e 1980.

O movimento videoarte nos Estados Unidos nas décadas de 1960 e 1970 compreende não apenas o vídeo, como também o uso de computadores, holografia e muitas outras tecnologias gráficas e sonoras. Seus líderes John Cage, William Burroughs e Michael Shamberg estavam interessados em utilizar artisticamente as novas tecnologias para desestabilizar a hegemonia das 
mídias de massa, de acordo com as propostas da contracultura, ainda que o papel do vídeo certamente não seja substituir a fotografia ou o cinema como formas de documentação dos fatos. Menos ainda, reduz-se a um simples difusor das produções cinematográficas, como tem sido feito normalmente até hoje. No entanto, mesmo antes que o vídeo pudesse mostrar realmente a que veio, de que forma poderia responder aos anseios de uma nova arte, a imagem eletrônica já estava se integrando às linguagens da fotografia e do cinema. Parece que tudo se torna uma coisa só, sob a denominação abrangente de multimídia. Surge um espaço amplo e fértil para as novas formas expressivas e representativas em que:

a tela mosaicada da televisão representa hoje o local de convergência de todos os novos saberes e da sensibilidade emergentes que perfazem o panorama da visualidade deste final de século. Se isso é bom ou é mau, se há aí sinais de progresso ou de catástrofe, é tudo uma discussão ética que cabe aos filósofos da pós-modernidade. ${ }^{*}$

" Machado, Arlindo. Má quina e imaginário. Ob. cit.: 48).

Um dos aspectos mais relevantes da imagem videográfica é a metamorfose, uma vez que, na pós-produção, é possível intervir infinitamente. Pode-se transformar o produto poético explicitandose o trabalho significante; pode-se inverter as relações, reestruturar seus elementos cromáticos, usar diversos tipos de superposições e imbricações, transparências, dispersões das imagens etc., pode-se, enfim, manipulá-los à exaustão, o que leva aos efeitos de saturação e a alguns excessos típicos da linguagem do vídeo.

Fala-se de um novo barroco ou, para os mais críticos, de um neomaneirismo que teriam como emblemas o recurso do chroma key, a inserção de imagens umas nas outras. Em termos de percepção, esse efeito de hibridismo e de imbricamento talvez seja o que marca mais profundamente a experiência da imagem eletrônica."

Temos, portanto, que as primeiras experiências poéticas que se valem da exploração de novas tecnologias, na segunda metade do século XX, confirmam a busca de um movimento que vá além do caráter bidimensional da página impressa. Nesse momento, começa a se estabelecer uma tênue distinção, até hoje ainda não completamente delineada, entre a videoarte e a videopoesia. O fenômeno passa a exercer certo fascínio sobre os poetas ligados aos experimentalismos e sincretismos por volta de 1960, que dedicam décadas aos ensaios em busca da tridimensionalidade e do movimento como tal, como, por exemplo, nos poemas holográficos e na videopoesia. 
Arlindo Machado afirma que é inadequado o termo vídeo (que, em latim, significa eu vejo) para designar a experiência possibilitada por esse meio de expressão. Enquanto outros sistemas figurativos caminham na direção de uma hierarquização, em que o olho, separado dos demais sentidos, reina absoluto e solitário, "a arte do vídeo tende mais propriamente à sinestesia, ou seja, à reunificação dos sentidos".*

Em Portugal, Ernesto Melo e Castro vem realizando, desde 1968, experimentações com vídeo e produção poética criativa que envolvem signos verbais e não-verbais. Fazendo clara distinção entre videoarte e videopoesia, o poeta português considera a última uma experimentação a partir das poesias sonora, verbal e visual. Assim como a fotografia é julgada em oposição à pintura, o cinema ao teatro e o vídeo ao cinema, a videopoesia se refere diretamente à poesia experimental dos anos 1960 como texto iconizado.

Também em Portugal, uma teoria do tex to computadorizado foi desenvolvida por Pedro Barbosa em seu livro A ciberliteratura* . O poeta compõe um painel abrangente sobre os métodos e algoritmos para a criação literária computacional, e investiga os percursos textuais ligados à evolução dos softwares, para concluir com uma súmula de seu percurso pessoal como poeta e ficcionista cibernético.

No Brasil, algumas experiências poéticas podem ser consideradas paradigmáticas no percurso da poesia brasileira contemporânea em novos suportes. Lembremos as mais relevantes: no início dos anos 1980, quando tem início uma rede eletrônica planetária, Júlio Plaza organiza a exposição Arte pelo telefone, no MIS/SP e, em 1984, na XVII Bienal de São Paulo, a mostra Arte e videotexto, composta de videopoemas seus, de Paulo Leminski e de alguns poetas concretos, todos sonorizados por sintetizadores. Em 1985, o resultado de algumas experiências pioneiras em videopoesia é apresentado na exposição Transcriar, no Centro Cultural São Paulo. Entre 1992 e 1994, são realizadas experiências com vídeo poesia no Laboratório de Sistemas Integráveis, da Escola Politécnica da USP. ${ }^{3}$

Em 1993, é lançado o videohome NOME, de Arnaldo Antunes, que acompanhou o livro e o CD de mesmo título. Trata-se

\footnotetext{
${ }^{3}$ Esses exemplos pioneiros de produção/transcriação de poemas visuais em novos suportes estão relatados no livro de Ricardo Araújo Poesia visual. Vídeo poesia, publicado em 1999. O resultado dessa associação de pesquisadores da Engenharia Eletrônica e da Arquitetura a um grupo de poetas ligados à poesia concreta é um conjunto de sete poemas para vídeo.
} 
do primeiro lançamento no circuito comercial de uma produção poética multimidiática. Em agosto de 1994, o Perhappiness, evento da Fundação Cultural de Curitiba, em sua sexta edição, apresenta uma poesia para ver, ouvir, ler e sentir. O público curitibano toma conhecimento de que, quando as palavras são lidas, ouvidas e ganham diversas formas e simultaneidade graças ao computador, alguma coisa está acontecendo no reino da poesia.

Em 1997, na mostra Arte-Suporte-Computador, na Casa das Rosas, em São Paulo, Augusto de Campos expõe seus clipoemas digitais. Na sequiência, merece destaque a Mostra de Videopoesia 2.000, realizada no MIS-SP, com curadoria de Enzo Minarelli e Philadelpho Menezes.

A Fundação Cultural de Curitiba promove, em 2001 e 2002, o Concurso Nacional de Clipoemas, idealizado por Décio Pignatari, com assessoria de Rosana Albuquerque e equipe. Trata-se de um momento paradigmático no percurso das poéticas tecnológicas que se desenvolviam no país. Na ocasião, o público curitibano tem acesso a uma amostra do que era feito e uma percepção do que seria possível realizar em termos de poesia multimídia.

É preciso lembrar também o FILE*, o Festival Internacional " (Cf. http://www.file.com.br) de Linguagens Eletrônicas, que reúne grande variedade de formas artísticas de todo o mundo. O FILE tem uma proposta de trabalho que não ultrapassa os limites dos computadores: são obras artísticas disponíveis na rede e que só fazem sentido no ciberespaço, no qual se desenvolveram.

Nos últimos anos, surgiram alguns sites na internet que apresentam poemas visuais e tecnológicos: alguns só com movimento, outros integrando sonoridades, mas é preciso ressalvar que não basta colocar os poemas na rede ou nas telas para que sejam tidos como poesia multimídia. Trata-se não de simplesmente substituir o papel por outro suporte, mas sim de incorporar os modos de criação poética e os critérios de seleção dos componentes tecnológicos utilizados. O processo implica uma consciência intersemiótica agindo sobre uma experiência poética que incorpora sintaticamente características de software, ou seja, uma sintaxe mutante baseada em linguagens de programação que se adiciona aos elementos sensoriais da obra poética.

Os desdobramentos das poéticas experimentais em multimeios são controversos, oscilando entre propostas poéticas de cunho fundamentalmente estetizante, outras de caráter mais espetaculoso e, ainda, radicalizações que se apropriam das tecnologias das instalações multimidiáticas em nome de uma poesia sinestésica. Hoje, o hibridismo das poéticas videográficas, 
"Plaza, Júlio e Tavares, Mônica. Processos criativos com os meios eletrônicos: poéticas digitais. São Pau. lo: Hucitec, 2000: 63). que realizam a mescla criativa entre a linguagem verbal e as linguagens do cinema, da televisão e das multimídias, demanda um tratamento diferenciado de caráter (inter)semiótico, uma vez que é nesses pressupostos teóricos que se encontra apoio não só para a leitura dos diferentes tipos de signos, mas sobretudo para os modos como eles se integram na constituição dessas novíssimas linguagens híbridas.

\section{Considerações finais}

A contínua busca por novos suportes, desde a consolidação da instalação, do objeto e da performance nos anos 1960 até o aparecimento da videoarte entre 1970 e 1980, tem sido marcante na arte contemporânea. Na última década do século XX, a arte eletrônica e a multimídia ampliaram radicalmente o alcance das obras, tornando sutis os limites entre o uso estético das novas mídias e o apelo da novidade tecnológica em si. A tecnologia envelhece rapidamente e se descartam facilmente os recursos que acabaram de causar grande agitação no terreno da arte. Além disso, diante das mídias eletrônicas, a percepção humana passa por profundas alterações. Ao manipular mais signos que coisas, o homem, em crise de identidade, adquire uma sensibilidade frágil. A automatização na criação e na percepção das obras revela a necessidade da humanização das tecnologias, em termos de uma poética tecnológica que "desautomatize" os processos de transmissão de conhecimento e a própria atividade cognitiva. Na verdade, o meio eletrônico, como qualquer outro meio, permite variados approachs. A sensibilidade para criar algo genial é tão difícil como em qualquer outra área. O que importa é a capacidade de desenvolver obras singulares, longe da adesão fácil à tecnologia e dos formalismos provincianos. Desse modo, os novos suportes podem ser utilizados em nome da expressão, e não pela novidade em si. Afinal, como assinalam Plaza e Tavares, em seu abrangente estudo sobre os processos criativos com os meios eletrônicos:

Nos processos criativos com estes meios, a qualidade é evidenciada como compromisso estabelecido entre a subjetividade daquele que inventa e as regras sintáticas inerentes aos programas por ele utilizados. Estas tecnologias, ao participarem deste tipo de criação, instituem-se como formas de expressão, manifestadas pelo diálogo ente a materialidade do meio e o insight criativo.* 
Há fortes motivos para vermos com otimismo o desempenho da literatura nos novos suportes. Percebemos claramente, no entanto, que a ampliação do espaço da ciberliteratura tem esbarrado na mera transferência de obras do papel para a tela, sem que haja a devida consciência dos recursos multimidiáticos e/ou hipertextuais. Ainda há muito a fazer no que tange à criação de textos literários, cuja realização plena só se dá nos multimeios ou na internet. Trata-se de textos pensados exclusivamente para os novos suportes, e não pura e simplesmente transferidos para as telas, que já podem ser encontrados em alguns endereços de sites pouco conhecidos*, bem como em CDRoms, DVDs e produtos similares, ainda raros no mercado. 
Palavras-chave ciberliteratura, narrativas hipertextuais, poesia multimídia

Key words

Cyberculture, hypertext narratives, multimidia poetry

Palabras clave ciberliteratura, narrati. vas hipertextuales, poesía multimedia
Recebido em 31/05/2005

Aprovado em 30/06/2005

Denise Azevedo Duarte Guimarães

Doutora em Letras. Professora aposentada da UFPr, leciona na Universidade Tuiuti do Paraná. Criou e editou a Revista Estudos Brasileiros, da UFPr, que teve 13 números publicados, de 1976 a 1982. Criou e edita, desde 2000, a Revista Eletrônica semestral: e-letras, da UTP. Possui mais de cem artigos publicados e, entre outros, os livros A poesia crítico-inventiva (Curitiba: SEC/BPPR, 1985) e, com Angélica Soares, Poesia: crítica e autocrítica (Curitiba: Scientia et Labor, 1989).

\section{Resumo}

O artigo estuda a emergência de novos paradigmas literários, procurando refletir acerca das textualidades contemporâneas. Focaliza os hipertextos informatizados e a poesia multimídia, com o intuito de desvendar como estão sendo criados novos procedimentos expressivos e em que medida eles podem ser identificados com reflexões teóricas anteriores acerca do texto literário impresso. Remete a questões ligadas à leitura dos diferentes tipos de signos e aos modos como eles se integram para a constituição dessas novíssimas linguagens híbridas em novos suportes.

\section{Abstract}

This article investigates the emergence of new literary paradigms as it tries to understand new contemporary textualities. It analyses some hypertexts and multimedia poetry trying to trace how new expressive procedures are being created. How can these new languages be identified and what are their relations to previous theories which dealt with the literary printed text? This study approaches questions linked to the reading of different types of signs and the modes they function towards the fabrication of these new hybrid languages.

\section{Resumén}

El artículo estudia la emergencia de nuevos paradigmas literarios, procurando reflejar acerca de las textualidades contemporáneas. Enfoca los hipertextos informatizados y la poesía multimedia, intentando desvendar cómo están siendo creados nuevos procedimientos expresivos y en qué medida ellos pueden ser identificados a reflexiones teóricas anteriores acerca del texto literario impreso. Remite a cuestiones ligadas a la lectura de los diferentes tipos de signos y a los modos cómo ellos se interaccionan para la constitución de los novísimos lenguajes híbridos en nuevos supuestos. 